Ensino, Saúde e Ambiente - V10 (1), pp. 163-174, Abril. 2017

\title{
CONHECIMENTO DE ESTUDANTES SOBRE O USO DE AGROTÓXICOS PARA O PRODUTOR, CONSUMIDOR E MEIO AMBIENTE
}

\section{KNOWLEDGE OF STUDENTS ABOUT THE USE OF AGROCHEMICALS FOR THE PRODUCER, CONSUMER AND THE ENVIROMENT}

\author{
Luan Zimmermann Bortoluzzi ${ }^{1}$, Renato Xavier Coutinho ${ }^{2}$ \\ ${ }^{1}$ Instituto Federal Farroupilha, campus São Vicente do Sul - RS, luanbortoluzzi97@ gmail.com \\ ${ }^{2}$ Instituto Federal Farroupilha, campus São Vicente do Sul - RS, renato.coutinho@iffarroupilha.edu.br
}

\begin{abstract}
RESUMO
Os agrotóxicos são utilizados em quase todo o mundo, sendo o Brasil, segundo o Ministério do Meio Ambiente (MMA), o maior consumidor de produtos agrotóxicos do mundo. Pensando nisto, o presente trabalho teve como objetivo apresentar uma proposta pedagógica que teve como tema os agrotóxicos, informando alunos de $8^{\circ}$ e $9^{\circ}$ ano da escola São Vicente, da cidade de São Vicente do Sul-RS, Brasil, sobre os malefícios do uso destes agentes químicos para o consumidor, produtor e para o Meio Ambiente a curto e longo prazo, bem como apresentar produtos orgânicos como forma alternativa aos produtos convencionais. Para isto, foram utilizadas de palestras para informá-los sobre as consequências destes agentes, tendo ao final destas, a aplicação de questionários, visando saber se os objetivos da pesquisa foram alcançados. Constatou-se que $90 \%$ dos alunos entrevistados afirmaram que as palestras dadas foram de suma importância para seu conhecimento sobre o assunto, tendo $28 \%$ dos entrevistados que não sabiam das consequências destes agentes antes de assistirem à palestra, onde $80 \%$ destes pensarão em mudar seus hábitos alimentares, optando por alimentos mais saudáveis. Por mais polêmico e debatido que seja este assunto, este, acaba muitas vezes, não recebendo a devida atenção e preocupação por parte dos jovens e, se não forem constantemente informados sobre a importância de se estudar esse assunto, teremos uma nova geração de adultos com hábitos alimentares prejudiciais a sua saúde ao meio ambiente.
\end{abstract}

Palavras-chave: Agrotóxicos; Hábitos alimentares; Produtos orgânicos.

\begin{abstract}
The agrochemicals are used almost everywhere in the world, Brazil being the largest consumer of pesticides in the world, according to the Ministry of the Environment (MMA). The objective of this study was to present a pedagogical proposal that had the theme of pesticides, informing 8th and 9th grade students of São Vicente School, in the São Vicente do Sul city, Brazil, about the harmful effects of using these pesticides. Chemical agents for consumer, producer and the environment the short and long term, as well as presenting organic products as an alternative to conventional products. For this purpose, lectures were used to inform them about the consequences of these agents, having at the end of these lectures, the application of questionnaires, in order to know if the research objectives were reached. It was found that $90 \%$ of the students interviewed stated that the lectures given were of great importance for their knowledge on the subject, with $28 \%$ of those interviewed who did not know the consequences of these agents before attending the lecture, where $80 \%$ of them will think about changing their eating habits by opting for healthier food. However controversial and debated this subject is, it often ends up not getting the attention and concern of young people, and if
\end{abstract}


they are not constantly informed about the importance of studying this subject, we will have a new generation of adults with eating habits that are detrimental to their health and to the environment.

Key words: Pesticides; Eating habits; Organic products.

\section{INTRODUÇÃO}

Vivemos em mundo cercado pela utilização de agrotóxicos, os quais estão disseminados em todos os tipos de ambientes, podendo ter como função a proteção de florestas nativas, da silvicultura, de ambientes hídricos (tratamento de água em ambientes urbanos, domiciliares e coletivos) e no beneficiamento de pastagens e de produtos agrícolas. Estes agentes químicos antes denominados defensivos agrícolas, passaram a ser chamados de agrotóxicos devido às consequências de seu uso, as quais contradiziam seu nome:

O termo defensivo agrícola carrega uma conotação errônea de que as plantas são completamente vulneráveis a pragas e doenças, e esconde os efeitos negativos à saúde humana e ao meio ambiente. O termo agrotóxico é mais ético, honesto e esclarecedor, tanto para os agricultores como para os consumidores. (Informativo CRQ III, 1997).

Nesse sentido, os agrotóxicos são segundo o Ministério do Meio Ambiente (MMA) os produtos e agentes de processos físicos, químicos ou biológicos, utilizados nos setores de produção, armazenamento e beneficiamento de produtos agrícolas.

O controle de pragas nocivas à agricultura é utilizado desde o início da civilização tendo como exemplo, a fumaça utilizada pelos egípcios para o controle de insetos em seus cultivos. Durante anos os seres humanos usaram de forma indiscriminada esses agentes químicos, sem verificar as consequências para com o Meio Ambiente.

Os agrotóxicos englobam muitas substâncias químicas, substâncias estas que são classificadas pelo tipo de praga que controlam e pelos efeitos à saúde humana e ao meio ambiente. Estes agentes são classificados quanto à praga combatida e ao grupo químico a que pertencem, onde os inseticidas, fungicidas e herbicidas, além de serem os mais empregados mundialmente, são também os que mais causam doenças agudas e crônicas, pois como atuam diretamente sobre processos vitais, esses venenos têm ação sobre a constituição física e a saúde do ser humano (PERES, MOREIRA \& DUBOIS, 2003).

Folgado (2014) diz que os agrotóxicos "geram um conjunto de problemas sociais, ambientais, econômicos, entre outros, mas que em sua grande maioria são 


\section{Ensino, Saúde e Ambiente - V10 (1), pp. 163-174, Abril. 2017}

pouco estudados e até mesmo invisibilizados, muito em função dos interesses e poderes (econômicos)". Isto acaba se agravando ainda mais, pois países que utilizam uma grande quantia desses agentes acabam deixando de lado esses problemas, que consequentemente irão afetar aos que tem contato direto e indireto com esses produtos.

Segundo o MMA (2016), o Brasil é o maior consumidor de produtos agrotóxicos do mundo, sendo este um problema já que grande parte dos pesticidas usados legalmente no país foi proibida na Europa, Ásia e América do Norte.

Os produtores utilizam os agroquímicos a fim de aumentar sua produção, contudo o uso indiscriminado desses agrotóxicos tem graves consequências para os consumidores, como é afirmado no trecho:

Apesar da grande importância das atividades agrícolas, há pouco interesse no estudo de aspectos da saúde e segurança na agricultura. Existe grande interesse em desenvolver novas tecnologias para aumento da produção na agropecuária, sem levar em consideração os impactos à saúde e à segurança do trabalhador (FRANK et al., 2004).

Silveira-Filho (2011) diz que "Para fortalecer o vínculo positivo entre a educação e a saúde, deve-se promover um ambiente saudável melhorando a educação e o potencial de aprendizagem, ao mesmo tempo em que promovem a saúde". Portanto, é importante desde cedo, que a escola fale sobre as consequências dos agrotóxicos assim como vários outros temas direcionados à preservação ambiental e a proteção do homem. É a partir da Educação Ambiental que os alunos começarão a ver as consequências do uso destes agentes químicos, e, por conseguinte a ter mais consciência sobre a importância de preservar o ambiente em que vivem e terem uma alimentação mais saudável.

É importante que a realização de atividades sobre o tema abordado seja de forma interdisciplinar, para que o aluno veja a dimensão que o assunto tem, não ficando restrito somente a parte biológica do assunto. Neste sentido, a integração das disciplinas de biologia e química assim como outras, daria maior possibilidade de trabalhar vários aspectos de um mesmo tema, de modo que os alunos tenham uma visão mais ampla sobre os problemas que os cercam:

Tratando o assunto proposto, o aluno teria a oportunidade de adquirir o conhecimento químico conhecendo mais sobre os elementos químicos presentes nos principais defensivos agrícolas, assim como os malefícios relacionados com a saúde causados pela manipulação desses defensivos. Através do assunto agrotóxico o discente teria a oportunidade de adquirir uma visão mais critica perante os problemas que o rodeiam (NEVES, 2010). 
A utilização de agrotóxicos está muito presente na produção agrícola da cidade de São Vicente do Sul-RS, Brasil, sendo esta, de acordo com o Instituto Brasileiro de Geografia e Estatística (IBGE, 2016), uma cidade pequena com aproximadamente 8.802 pessoas, com 40\% do seu Produto Interno Bruto (PIB) destinado à Agropecuária.

Sendo assim, esta pesquisa tem como objetivo apresentar uma proposta pedagógica que teve como tema os agrotóxicos, buscando mostrar aos estudantes as consequências do uso indiscriminado desses materiais, bem como as diferenças de um agrotóxico para outro, maneiras mais sustentáveis para a produção agrícola em menor e maior escala e, por conseguinte, a conscientização dessa população em vistas à transformação dos hábitos dessa comunidade.

\section{METODOLOGIA}

A pesquisa foi feita por meio do método dedutivo, segundo Diniz e Da Silva (2008) este é "o método dedutivo parte das teorias e leis consideradas gerais e universais buscando explicar a ocorrência de fenômenos particulares". Sendo assim, foi escolhido esse método pelo fato do tema ser alvo de muitos artigos e ser um assunto discutido mundialmente. Assim, a pesquisa buscou em fontes bem gerais (sendo esses abordados em todos os lugares que se utilizam agrotóxicos), até chegar ao objetivo principal da pesquisa.

O projeto teve como público-alvo estudantes de oitavo e nono ano, do ensino fundamental de uma escola pública do município de São Vicente do Sul, RS.

A presente proposta pedagógica foi desenvolvida em duas etapas: 1) Palestras sobre o tema agrotóxicos, a fim de abordar os conceitos pertinentes ao tema, bem como sensibilizar o público-alvo do trabalho acerca do tema; 2) Aplicação de questionários para identificar as percepções dos estudantes sobre o assunto.

\section{RESULTADOS E DISCUSSÃO}

A primeira etapa, onde foram realizadas duas palestras sendo uma para duas turmas do turno da manhã, contando 36 alunos. A segunda foi para duas turmas do turno da tarde, com 33 alunos presentes.

As palestras tiveram $1 \mathrm{hr}$ e $20 \mathrm{~min}$ de duração, tendo como temas os seguintes tópicos:

1. Surgimento dos agrotóxicos (como, onde e o porquê do seu surgimento); 
Ensino, Saúde e Ambiente - V10 (1), pp. 163-174, Abril. 2017

2. Agrotóxicos mais utilizados e danosos para o ambiente, produtores e consumidores no Brasil e no mundo;

3. Consequências do uso indiscriminado destes produtos aos consumidores, produtores (doenças agudas e crônicas) e ao ambiente a curto e longo prazo;

4. Apresentação dos produtos orgânicos como forma alternativa e eco sustentável para o consumo e produção (o que são? Vantagens e desvantagens em comparação aos alimentos convencionais? Mitos e verdades?).

A segunda etapa da prática corresponde à aplicação do questionário aos alunos, logo após o término das palestras. Todos os alunos presentes responderam ao questionário.

A primeira questão buscou saber se os alunos estavam conscientes sobre os malefícios do uso indiscriminado de agrotóxicos para o produtor, consumidor e Meio Ambiente antes de participarem da palestra. Os resultados desta análise são apresentados na Tabela 1.

Tabela 1: Consciência dos alunos sobre os malefícios do uso indiscriminado de agrotóxicos, tanto para o produtor, consumidor e Meio Ambiente antes de participarem da palestra.

\begin{tabular}{lc}
\multicolumn{1}{c|}{ Respostas } & \%Alunos n \\
\hline Sim & $29(20)$ \\
Não & $28(19)$ \\
Um pouco & $43(30)$ \\
\hline Total & $100(69)$ \\
\hline
\end{tabular}

Fonte: Dados da Pesquisa.

Identifica-se que apenas $29 \%$ dos alunos entrevistados sabiam das consequências do uso indiscriminado de agrotóxicos para o ambiente, bem como para a saúde do consumidor e produtor, e que $43 \%$ dos alunos sabiam um pouco destas consequências. O mais alarmante é o percentual deles (28\%) que não sabiam as consequências do uso destes agentes químicos antes de participarem da palestra.

Um estudo feito por Augusto \& Preza (2012) aponta que 80\% das pessoas que participaram de seu estudo, não tinham um nível de conhecimento apropriado sobre informações acerca das características dos agrotóxicos, de sua nocividade, o que deve ser considerado de relevância quando forem programadas ações de promoção e proteção à saúde, tanto para consumidores como para produtores.

Outro estudo dirigido por Barbosa (2011) aponta que após suas atividades de conscientização com alunos que se tornarão técnicos agrícolas, estes, entenderam que 
atividades agrícolas causam danos ao meio ambiente e também à sociedade, quando trazido este assunto para suas realidades, por exemplo, a abordagem dos trabalhadores das plantações de cana de açúcar ou pequenos agricultores que vivem de subsistência.

A segunda questão buscou saber se as palestras realizadas contribuíram para o conhecimento dos alunos sobre a temática agrotóxicos. Os resultados dessa análise são apresentados na Tabela 2.

Tabela 2: Contribuição das palestras para um conhecimento mais aprofundado sobre os agrotóxicos.

\begin{tabular}{l|c}
\multicolumn{1}{c|}{ Respostas } & \%Alunos n \\
\hline Sim & $90(62)$ \\
Não & $01(01)$ \\
Um pouco & $09(06)$ \\
\hline Total & $100(69)$ \\
\hline
\end{tabular}

\section{Fonte: Dados da Pesquisa.}

Observou-se que $90 \%$ dos alunos entrevistados afirmaram que as palestras foram de grande contribuição para o seu conhecimento sobre o assunto, sendo que nem todos conheciam algumas questões polêmicas sobre os agrotóxicos, tais como: os mais danosos e utilizados no Brasil e no mundo; as consequências destes para o produtor, consumidor e meio ambiente e vantagens e desvantagens quando comparados aos produtos orgânicos, fazendo com que após as atividades eles desenvolvessem um olhar crítico sobre o assunto.

Em um estudo dirigido por Piatti et al. (2008), demonstra que palestras, assim como outras atividades, contribuem para seu conhecimento sobre o assunto trabalhado, bem como para a tomada de consciência. Rossasi \& Polinarski (2011) em seu estudo afirmam que aulas/palestras tradicionais, as quais o expositor não interage com o aluno (não utilizando da didática), acabam fazendo com que este não pense de forma lógica e crítica sobre o assunto, tornando as aulas/palestras massivas e desinteressantes.

A terceira questão buscou identificar quantos alunos consomem, não consomem ou consomem poucas vezes alimentos orgânicos. Os resultados dessa análise são apresentados na Tabela 3 .

Tabela 3: Consumo de alimentos orgânicos dos alunos de $8^{\circ}$ e $9^{\circ}$.

\begin{tabular}{lc}
\multicolumn{1}{c}{ Respostas } & \%Alunos no \\
\hline Consomem & $62(43)$ \\
Não consomem & $06(04)$ \\
Às vezes & $32(22)$ \\
\hline Total & $100(69)$ \\
\hline
\end{tabular}

Fonte: Dados da Pesquisa. 
A partir dos dados obtidos, verifica-se que $62 \%$ dos alunos entrevistados consumem alimentos orgânicos (Tabela 3), isso se deve em parte, ao fato de que muitos desses alunos já convivem com projetos relacionados ao consumo de alimentos orgânicos no âmbito escolar e familiar.

De acordo com o trabalho de Oliveira et al. (2006) e Guimarães et al. (2013), pessoas com idade acima de 50 anos, são as que mais consomem produtos orgânicos, levando em consideração que o nível de consciência que estes adquirem aumenta com o passar dos anos. Os autores também indicam que pessoas com maior tempo de escolarização, tendem a ter mais consciência sobre as consequências para a saúde do consumo de alimentos com agrotóxicos, optando por alimentos orgânicos. Segundo os autores, as variáveis demográficas e socioeconômicas também estão relacionadas, onde pessoas de classe A, B e $\mathrm{C}$ tendem a consumir mais esses produtos do que as de classes inferiores.

A quarta questão buscou identificar a porcentagem de alunos que compram legumes, hortaliças e frutas que consomem. Os resultados dessa análise são apresentados na Tabela 4.

Tabela 4: Alunos que compram legumes, hortaliças e frutas que consomem.

\begin{tabular}{lcc} 
& Respostas & \%Alunos n \\
\hline Sim & $55(38)$ \\
Não & $09(06)$ \\
Ãs vezes & & $36(25)$ \\
\hline Total & $100(69)$ \\
\hline
\end{tabular}

Fonte: Dados da Pesquisa.

A partir dos dados obtidos, observa-se que 55\% dos alunos compram os legumes, hortaliças e frutas que consomem; $36 \%$ compram de vez em quando e apenas $9 \%$ dos alunos entrevistados não compram estes alimentos que consomem.

Henz e Alcantara (2009) dizem que a oferta de alguns alimentos há alguns anos, como frutas e hortaliças, era irregular e sazonal, fazendo com que as pessoas acabassem produzindo seu próprio alimento nos quintais de suas casas, onde com a produção destes alimentos, além de mais baratos, o consumidor tinha conhecimento da procedência destes e controlava melhor a qualidade do alimento quando produzido em sua própria residência. Porém, essa prática comum a quase todas as famílias brasileiras quase foi perdida pela falta de espaço nos centros urbanos e pelos novos meios de vida das pessoas. 
A quinta questão buscou identificar quais alunos que, após a palestra pensarão em cultivar uma horta em casa, evitando assim, a compra de alimentos produzidos de forma convencional. Os resultados dessa análise são apresentados na Tabela 5.

Tabela 5: Cultivo de horta em casa à compra de alimentos não orgânicos após assistirem a palestra.

\begin{tabular}{lcc}
\multicolumn{1}{c|}{ Respostas } & \%Alunos $\mathbf{~ n}^{\mathbf{0}}$ \\
\hline Sim & $82(57)$ \\
Não & $09(06)$ \\
Depende & $09(06)$ \\
\hline Total & $100(69)$ \\
\hline
\end{tabular}

\section{Fonte: Dados da Pesquisa.}

Percebe-se que $82 \%$ dos alunos entrevistados, após a palestra perceberam os benefícios de se ter uma horta em casa à compra de alimentos em feiras, mercados, pois estes são livres de quaisquer agentes químicos e agrotóxicos, cabendo ao responsável pelo cuidado das hortaliças, produzindo-as de uma forma sustentável. Os alunos que marcaram a alternativa "depende" não justificaram suas respostas.

Makishima (2005) em seu estudo diz que ter uma horta em casa não é somente uma forma de economizar. É ter facilidades para preparar as refeições com diversos produtos.

A sexta questão buscou identificar a porcentagem de alunos que conheciam produtores orgânicos na cidade. Os resultados dessa análise são apresentados na Tabela 6.

Tabela 6: Conhecimento de produtores orgânicos por parte dos alunos.

\begin{tabular}{lc}
\multicolumn{1}{c|}{ Respostas } & \%Alunos n \\
\hline Sim & $57(39)$ \\
Não & $43(30)$ \\
\hline Total & $100(69)$ \\
\hline
\end{tabular}

Fonte: Dados da Pesquisa.

Analisando os dados, verifica-se que 57\% dos alunos entrevistados afirmaram que conheciam produtores de alimentos orgânicos. Não foram especificados quantos por cada um destes. Isso deve-se em parte, por serem moradores de uma cidade pequena, onde muitos dos pais destes alunos e demais moradores da cidade, trabalham ou tem algum vínculo com o meio rural.

Finatto e Corrêa (2010) apontam em seu estudo uma crescente demanda de produtos orgânicos por interesse dos consumidores. Os agricultores de alimentos orgânicos da região estudada vão semanalmente para alguns pontos da cidade vender seus produtos, sendo que estas feiras ecológicas estão aumentando. 
A sétima questão buscou identificar os alunos que, após apalestra, pensarão em mudar seus hábitos alimentares, optando por alimentos orgânicos. Os resultados dessa análise são apresentados na Tabela 7.

Tabela 7: Alunos que, após a palestra, pensarão em mudar sua alimentação, optando por alimentos orgânicos.

\begin{tabular}{l|c}
\multicolumn{1}{c|}{ Alternativas } & \%Alunos no \\
\hline Sim & $80(55)$ \\
Não & $20(14)$ \\
\hline Total & $100(69)$ \\
\hline
\end{tabular}

Fonte: Dados da Pesquisa.

Quando questionados sobre a mudança de seus hábitos alimentares, optando por alimentos orgânicos, constata-se que a maioria dos alunos pensará em modificá-los.

Um estudo feito por Neutzling et. al (2009) aponta que, a partir das pessoas entrevistadas em feiras de produtos orgânicos na cidade de Porto Alegre-RS, Brasil, $74 \%$ dos entrevistados compram alimentos orgânicos de 3 a 5 vezes ao mês, o que demonstra a mudança dos hábitos alimentares das pessoas, tanto de cidades pequenas (que tem mais contato e facilidade de conseguir alimentos orgânicos), como de cidades grandes, onde estão cada vez mais optando por uma alimentação saudável.

A oitava questão buscou saber se os alunos após a palestra repassarão os conhecimentos adquiridos sobre os agrotóxicos, bem como os alimentos orgânicos para familiares, amigos e vizinhos. Os resultados dessa análise são representados na Tabela 8 .

Tabela 8: Alunos que, após a palestra, repassarão seus conhecimentos sobre o assunto para familiares, amigos, vizinhos.

\begin{tabular}{lcc}
\multicolumn{1}{c}{ Alternativas } & \%Alunos no \\
\hline Sim & $86(59)$ \\
Não & $14(10)$ \\
\hline Total & $100(69)$ \\
\hline
\end{tabular}

\section{Fonte: Dados da Pesquisa.}

De todos os entrevistados, $86 \%$ dos alunos afirmaram que irão repassar o conhecimento que adquiriram na palestra para familiares, amigos e vizinhos. Isto mostra o quão eficaz é a utilização de palestras para ensinar, repassar o conhecimento e sensibilizar os ouvintes.

Um estudo feito por Caldeira (2011) mostra que alunos após participarem de palestras começam a mudar suas percepções e seus hábitos, mudando positivamente sua conduta. Sendo que através das palestras os alunos aprendem novos conceitos, fazendo eles refletirem sobre sua vida social e atividades extracurriculares. 


\section{CONSIDERAÇÕES FINAIS}

Com a realização deste estudo foi possível verificar a efetividade da palestra sobre a temática agrotóxicos, pois os estudantes aprenderam e discutiram sobre as consequências desses agentes para a saúde e o meio ambiente, sendo este um assunto que deve ser debatido com frequência em sala de aula para que as futuras gerações aprendam a viver em harmonia com o ambiente, e que se possa continuar com a produção de alimentos da forma mais eco sustentável possível.

Observou-se que mesmo a pesquisa sendo desenvolvida em uma cidade onde a agricultura tem um espaço amplo, muitos alunos não sabiam das várias consequências causadas pela utilização dos agrotóxicos ao produtor, consumidor e ao Meio Ambiente. É importante salientar, que mesmo muitos tendo esse desconhecimento, boa parte possui hortas em casa e/ou consomem alimentos orgânicos, algo que deve ser estimulado cada vez mais pelos professores, através de hortas comunitárias, escolares e a produção de uma composteira no âmbito escolar. Fato que deve ser considerado pelos professores ao trabalharem o tema na escola.

É sabido que apenas com a realização de palestras não se pode conscientizar a todos, por isso é importante que os professores façam essas intervenções ao longo do ano letivo, para que a consciência dos alunos sobre este tema fique ainda mais evidente em suas ações e que isso seja levado para as suas famílias.

Destaca-se a importância que essas intervenções sejam feitas de forma interdisciplinar, para que os alunos vejam a dimensão que o assunto atinge ao ser trabalhado desta forma e, por conseguinte, ter resultados ainda melhores.

Assim, após este trabalho espera-se que haja uma ampliação dos debates acerca do tema na escola, que envolvam profissionais da área da agricultura, saúde e educação.

\section{REFERÊNCIAS}

AMBIENTE, M. do M. Agrotóxicos. Disponível em http://www.mma.gov.br/seguranca-quimica/agrotoxicos. Acesso em 15 setembro de2016.

BARBOSA, L.C.A.; PIRES, D.X. O uso da fotografia como recurso didático para a educação ambiental: uma experiência em busca da educação problematizadora. Revista Experiências em Ensino de Ciências-V6 (1), p. 69-84. 2011. 
CALDEIRA, M. K. S. Avaliação dos efeitos das palestras da dretoria de educação ambiental do Instituto Brasília Ambiental-IBRAM-na sensibilização ambiental de estudantes de ensino médio. 2015. Disponível

emhttp://repositorio.uniceub.br/jspui/bitstream/235/6310/1/20840400.pdf. Acesso em 05 de janeiro de 2017.

DA SILVA AUGUSTO, L.G. Vulnerabilidades de trabalhadores rurais frente ao uso de agrotóxicos na produção de hortaliças em região do Nordeste do Brasil. Rev. bras. Saúde ocup, v. 37, n. 125, p. 89-98. 2012.

DE OLIVEIRa, R. A., LIMA, P. V. P. S., \& SILVA, L. M. R. O Consumo E Comercialização De Produtos Orgânicos: O Caso Da Associação Para O Desenvolvimento Da Agropecuária Orgânica-Fortaleza. In 44th Congress, July 23-27, 2006, Fortaleza, Ceará, Brazil (No. 149303). Sociedade Brasileira de Economia, Administracao e Sociologia Rural (SOBER). 2006.

DINIZ, C.R.; DA SILVA, I.B. Tipos de métodos e sua aplicação. Campina Grande, Natal. 2008. Disponível em

http://www.ead.uepb.edu.br/ava/arquivos/cursos/geografia/metodologia_cientifica/Met_ Cie_A04_M_WEB_310708.pdf. Acesso em 30 de dezembro de 2016.

FINATTO, R.A.; CORRÊA, W.K. Desafios e perspectivas para a comercialização de produtos de base agroecológica-O caso do município de Pelotas/RS. Revista Brasileira de Agroecologia, v. 5, n. 1. 2010.

FOLGADO, C.A.R. Agrotóxicos: Um problema invisibilizado. Brasilia-Distrito Federal. 2014. Disponível em http://www.brasilbio.com.br/pdfs/cartilha_agrotoxicos.pdf. Acesso em 30 de dezembro de 2016.

FRANK, A. L.; MCKNIGHT, R.; KIRKHORN, S. R.; GUNDERSON, P. Issues of agricultural safety and health. Annual Review of Public Health. Palo Alto, v. 25, p. 25-45. 2004.

GUIMARÃES, I. L. R.; DEFANTE, L. R.; SAUER, L.; \& DE OLIVEIRA LIMA FILHO, D. . Produtos orgânicos: como os consumidores os veem?. Revista Brasileira de Administração Científica, v. 4, n. 1, p. 50-61, 2013.

HENZ, G. P.; ALCÂNTARA, F. A. Hortas: o produtor pergunta, a Embrapa responde / editores técnicos,. - Brasília, DF: Embrapa Informação Tecnológica,. 237 p. : il. ; 22 $\mathrm{cm}$ - (Coleção 500 perguntas, 500 respostas). 2009.

IBGE-Instituto Brasileiro de Geografia e Estatística. Disponível em http://cidades.ibge.gov.br/painel/painel.php?lang=\&codmun=431980\&search=riogrande-do-sul|sao-vicente-do-sul|infograficos:-dados-gerais-do-municipio. Acesso em 23 de dezembro de 2016.

INFORMATIVO CRQ III. O dilema do uso de defensivos agrícolas. Rio de Janeiro: Conselho Regional de Química, III Região. 1997. Disponível em http://crq3.org.br/. Acesso em 24 de novembro de 2016. 
MAKISHIMA, N. Projeto horta solidária: cultivo de hortaliças. Jaguariúna: Embrapa Meio Ambiente. 2005.

NEUTZLING, D. M.; CALlADO, A. L. C., GAMARRA, J. E. T., \& RODRIGUEZ, I. C. Consumidor de Alimentos Orgânicos: um Estudo na Feira dos Agricultores Ecologistas (FAE) de Porto Alegre. In: CONGRESSO SOBER. 2009. Disponível em http://www.sober.org.br/palestra/15/770.pdf. Acesso em 22 de dezembro de 2016.

NEVES, P. A. P. F. G. das. O uso da Temática Agrotóxicos no Ensino de Ciências: A Concepção dos Alunos do Curso de Licenciatura Plena em Ciências Naturais. 2010. Disponível em http://www.sbq.org.br/eneq/xv/resumos/R0020-1.pdf. Acesso em 30 de dezembro de 2016.

PERES, F.; MOREIRA, J. C.; DUBOIS, G. S. Agrotóxicos, saúde e ambiente: uma introdução ao tema. É veneno ou é remédio, p. 21-41. 2003. Disponível em http://portal.fiocruz.br/sites/portal.fiocruz.br/files/documentos/cap_01_veneno_ou_reme dio.pdf. Acesso em 30 de dezembro de 2016.

PIATTI, T. M.; MERCADO, L. P. L.; OLIVEIRA, A. V.; SANTOS, A. A. dos; MURTA, E. G.; MONTE, G. M.; CAVALCANTE, M. C. M.; NITECY, G. de. A formação do professor pesquisador do ensino médio: uma pesquisa ação em educação e saúde. Revista Experiências em Ensino de Ciências - V3(1), pp. 23-41. 2008.

ROSSASI, L. B.; POLINARSKI, C. A. Reflexões sobre metodologias para o ensino de biologia: uma perspectiva a partir da prática docente. Porto Alegre: Lume UFRGS. 2011.

ROSSI, M. Agrotóxicos: o veneno que o Brasil ainda te incentiva a consumir. Disponível em http://brasil.elpais.com/brasil/2016/03/03/politica/1457029491_740118.html. Acesso em 15 de setembro de 2016. 